\title{
BANDEN TUSSCHEN ZUID-AFRIKA EN SURINAME IN VROEGER EEUWEN
}

DOOR

FRED. OUDSCHANS DENTZ

Wanneer men de lijst van stamvaders en stammoeders van Kaapsche geslachten tusschen de jaren 1657 en 1807 raadpleegt, uit welke geslachten de Boerenbevolking van de Zuidafrikaansche Unie-Kaapprovincie, Oranje Vrijstaat, Natal en Transvaal - is voortgesproten, dan kan men daarin tal van namen terugvinden van families die eertijds in Suriname woonden en thans zijn uitgestorven, alsmede van families, welke Suriname bewoond hebben en in Nederland zijn teruggekeerd of nog bewonen.

Behalve de vele Nederlanders die in de 17de en 18de eeuw naar Oost- en West-Indië en naar de Kaap de Goede Hoop trokken, waren er onder de kolonisten en ambtenaren tal van vreemdelingen, als Franschen, Duitschers, Zwitsers, Denen, Noren, Zweden die onder de Nederlanders zijn gehuwd en onder hen geheel zijn opgegaan.

Uit het in 1893/4 door Theal uitgegeven werk van den overleden Christoffel Coetzee de Villiers: Geslacht-Register der oude Kaapsche familien, heeft dr. H.T. Colenbrander de genealogieën van meer dan 1500 onderscheiden familiën nagegaan om daaruit de afkomst der Boeren vast te stellen ${ }^{\mathbf{1}}$ ).

In die lijst treffen wij één persoon aan die in Suriname geboren is, nl. Christiaan Benjamin Voltelen, die op 6 Febr. 1752 met Geertrui Susanna Meyboom huwde, in de Kaap geboren. Voltelen was eigenaar van een plantage in de Pauluskreek geweest. Een zijner zoons, Floris Jacobus

1) De Afkomst der Boeren, door dr. H. T. Colenbrander, Uitg. van het Alg. Ned. Verbond, No. 9, 1902. 
Voltelen, in 1754 te Zwartland in de Kaap geboren, waar zijn vader predikant was, werd een beroemd geneesheer te Utrecht en stierf 2 Aug. 1795 te Leiden ${ }^{1}$ ).

Afrikaners daarentegen, die naar Suriname zijn gegaan, zijn er ook geweest. Zoo zien wij dat leden van het geslacht Van den Heever uit de Kaap naar Suriname vertrokken zijn. De stamvader van dit geslacht, Jurriaan Pietersz. van den Heever, die uit Hoesum in Holstein kwam, huwde op 19 Nov. 1713 in de Kaap. Twee van zijn vrouwelijke nazaten hebben in Suriname geleefd en wel Anna Margaretha en Geertruyd van den Heever. De eerste was in Suriname gehuwd met een zekeren Beutler, en na diens dood huwde zij met Christiaan Frederik de Sydow uit het Brandenburgsche afkomstig; hun huwelijksaanteekening vinden wij in het volgend stuk ${ }^{2}$ ).

Op Heeden den 19e Maart 1762

Syn ten overstaan van de Edele achtb. C. E. de L. de Beauveser en D. J. W. Hatterman raaden in den Edele Hove van politie en Crimineele Justitie der Colonie Suriname door my ondergesz gesw. clercq ter secretary der gemelde Colonie na behoorlyke affvraaging tot den huwelyken staat in en aangetekent:

Christiaan Freedk. de Sydouw jongman van de Luytersche religie geboortig uyt Bierwaalde in het Brandenburgsche oud 28 jaaren en woonagtig alhier en

Anna Margaretha van den Heever, weduwe wylen Beutler oud 28 jaaren van de gereformeerde religie geboortig van de Caap de goede hoop en woonagtig alhier aan Paramaribo.

Actum paramaribo dato ut supra.

C. E. De Beauveser

D. W. J. HatTERMan my present

C. W. KOSTER

Gesw. clercq

1) Wapenbord van de voorzitters van het Utrechtsche Collegium Medicum, door dr. M. A. van Andel. Ned. Tijdschrift voor Geneeskunde, 4 Juli 1925 , No. 1.

2) Blz. 195 van het Register tot ondertrouw van de „Non Conformisten" 1742-1762 Rijksarchief No. 3. 
Van de beide kinderen hebben wij de volgende aanteekening in het doopregister der Luthersche gemeente te Paramaribo aangetroffen:

15 Aug. 1767 gedoopt Wigbolt Carel Frederik

Vader Christian Frederik de Sydow

Moeder Anna Margaretha van den Hever egtelieden ${ }^{\mathbf{1}}$ )

8 Febr. 1773 Tehuis gedoopt door Ds Kemper een kind genaamt

Andries Samuel Frederik

De vader Christiaan Frederik de Sydow geboortig van Bierwalden in 't Brandenburgsche

De moeder Anna Margaretha van den Heever, geboortig van de Caap de goede hoop. ${ }^{2}$ )

Anna Margaretha den Heever was als Kaapsche niet alleen in Suriname, toen haar zuster Geertruyd, met Joachim Friderici in November 1762 in de Kaap gehuwd, in Suriname kwamen en aldaar het geslacht (de) Friderici hebben voortgezet. Kwam Vaandrig Friderici reeds einde Juli 1763 te overlijden, Geertruyd zijn echtgenoote, volgde hem een week daarna. De zoon Juriaen François Friderici, een Zuidafrikaner van geboorte, werd in Suriname Gouverneur-Generaal.

Ook Anna Margaretha is niet oud geworden. Bij haar dood op 27 Nov. $1787^{3}$ ) was zij voor de tweede maal weduwe. In de Surinaamsche Nieuwsvertelder van Donderdag 19 April 1792 No. 359 lezen wij:

De crediteuren van de Boedel Wylen A. M. van den Heever Weduwe C. F. de Sydow werden verzogt het geene hun mogte competeeren, geduurende den 23 sten dezes tot den 15 den May van des Morgens 9 tot 12 uuren ter Nieuwe Wees Curateele \& Onbeheerde Boedelskamer te

\footnotetext{
$\left.{ }^{1}\right)$ Doopregister der Evangelisch-Luthersche gemeente van Paramaribo. $1743-1809$, blz. 44. Rijksarchief No. 14.

2) Ibidum, blz. 49 .

3) Grootboek van ontvangst van Kerkgerechtigheid blz. 334. R. A. No. 45 .
} 
komen ontfangen, zullende na dien Tyd de overschietende Saldos op afgeloopenen Boedels Reekening werden afgeschreeven.

Paramaribo den 19den April 1792.

J. H. T. PotTEndorfF.

Eerste Gesw. Klerk.

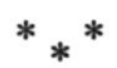

Meer dan een eeuw zou verloopen eer een ander Afrikaner zijn laatste rustplaats in Suriname zou vinden. Dat was de mijningenieur $\mathrm{C}$. W. Munnik, zoon van het tegenwoordig parlementslid, senator G. G. Munnik uit Pietersburg. In Nederland zijnde en tengevolge van den Boerenoorlog niet kunnende terugkeeren, vertrok hij naar Suriname als leider der exploitatie van de mijnontginningen der Mijnbouwmaatschappij „Suriname” en die van „Gran Placer". Munnik was Transvaler van geboorte en leider geweest van een bekende goudmijn in Transvaal. Reeds den 6den Augustus 1901 overleed hij aan zwartwaterkoorts en werd in het binnenland van Suriname begraven.

Met senator Munnik heb ik in Suriname nog gebriefwisseld en hem bijzonderheden medegedeeld over het overlijden van zijn zoon, welke tijdgenooten van hem mij hebben verschaft.

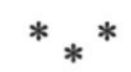

Onder de thans nog in Suriname bekende namen zie ik in de stamlijst van de Kaap de families Romond, Penard, Thirion, Conradie, Wessels, Treurniet, Schoon, Petzoldt, Rens, Bender, Arlaud, Zaal, Engelbrecht, Raadgever, enz.

De Penards, (Pinard) in Zuid-Afrika thans Pienaar geheeten, kwamen in 1688 uit Frankrijk.

Frederik Conradie, in 1699 vermeld, kwam uit Marburg, en was in 1715 in de Kaap met Hermina Harmens uit Dodewaard (Nederland) gehuwd, terwijl een Andreas Gottfried Coenradi uit Augsburg in 1783 met Anna Maria Elisabeth Slabbert in de Kaap gehuwd was. 
De Theronds (Theron, Tirion) kwamen uit Nimes (Frankrijk). Zij worden voor het eerst in 1690 in ZuidAfrika vermeld. Jacques Theron huwde in 1697 met Marie Jeanne du Pré, eveneens een Hugenoote. De familie Wessels komt in de Kaap vermeld voor in 1703, toen zoon van den Gouverneur, François van der Stel, die in 1706 uit de Kaap verbannen werd, in dat jaar met Johanna Wessels trouwde. Hendrik Treurniet uit Oostfriesland was in 1712 gehuwd met Catharina van Coningshoven van Mauritius, en Johannes Gerhardus Treurniet, eveneens uit Oostfriesland op 13 Februari 1775 met Dorothea van der Schyff uit de Kaap.

In 1735 zie ik Adam Jan Schoon uit Dohna (Saksen) geboortig met Anna Catharina Roelofse van de Kaap in het huwelijk stappen. Anna Catharina Petzold van Duitschland huwt 29 Augustus 1756 met Frederik Sigismund Modeman van Bernberg in Duitschland.

De familie Rens wordt in 1754 voor het eerst vermeld, terwijl Johan Adam Rens van Merseburg (Duitschland) op 25 Augustus 1761 met Elisabeth Catharina Lants huwde, in Nederland geboren. De familie Bender kwam uit Berlijn. Johan Hendrik Bender trad op 15 Februari 1761 met Beatrix Brand van de Kaap in den echt en wij zouden de benaming van plantage „Berlijn”, welke aan de familie Bender in Suriname heeft toebehoord wel als herinnering aan haar geboortestad mogen toeschrijven.

De Arlauds waren van Nieuw Levantijnschen oorsprong. Maria Elisabeth Arlaud van Konstantinopel, wordt vermeld in 1768 een huwelijk met Frans de Vrije uit Gouda te hebben aangegaan. Ook de Zaals kwamen uit Duitschland. Johanna Zaal huwt in 1768 met Lucas Steenkamp uit de Kaap. Catharina Elisabeth Engelbrecht, een Kaapsche, huwde op 31 Januari 1768 met Pieter Hendrik Heuning uit Lippstadt. Hun huwelijk werd met 11 kinderen gezegend. In 1708 huwde Gerrit Romond uit Nederland met Johanna Romond, eveneens uit Nederland afkomstig, terwijl in 1799 Carel Frederik Pohl uit Pruisen met Hester Isabella Marx uit de Kaap huwt. Ten slotte nog een greep uit de in Suriname bekende familie- 
namen en wel die van Raadgever. Francina Johanna Raadgever uit Nederland trad 28 November 1790 met Christiaan Gottlieb Höhne uit Dresden in het huwelijk.

Familienamen die ik in de Surinaamsche archieven heb aangetroffen en die thans niet meer in Suriname voorkomen waren: Hofmeyer, Coetzee, Stein, Roux, Celliers, Van Oudshoorn, De Cheusses, Krieger, Pistorius, du Plessis, Du Pree enz. Ten slotte de familie Reitz. Afkomstig uit Pommeren, vestigde deze zich in het begin der 18de eeuw in Nederland. Jan Frederik Reitz is de eerste die in de Kaapsche geslachtsregisters vermeld wordt. Hij kwam uit Utrecht en huwde in 1795 in de Kaap. Gysbert Christiaan Reitz voegde, op verlangen van zijn nicht Anna Gertruda Jacoba van den Bosch, haar naam bij den zijnen en voortaan heette het geslacht Bosch Reitz, waarvan een tak zich in Demerara en Suriname vestigde en tot op heden in Suriname nog voortleeft.

Zoo zijn er in den loop der eeuwen banden gelegd tusschen Kaapsche en Surinaamsche (Nederlandsche) geslachten, waarvan de speurder in de Surinaamsche archieven nog tal van voorbeelden zou kunnen geven en waarvan wij in dit kort bestek slechts enkele hebben opgesomd.

\footnotetext{
1) De volgende huwelijksaangifte van twee in Afrika geboren personen - evenwel niet op Zuid-Afrika betrekking hebbend - troffen wij aan in register No. 8, aanwezig in het Rijksarchief.

Staat van aangiften tot ondertrouw en van huwelijken, voltrokken door Gecommitteerden tot de Huwelyksche Zaken uit het Hof van Politie (1816-1827).

George van William van Weeth j.m. 35 j. R.C. geb. Madinga in Afrika en Anna Elisabeth van Linck j.d. 30 j. R.C. geb. in Afrika.

5 Sept. 1823 aangeteekend; 21 Sept. gehuwd.
} 